\title{
Papillary Thyroid Cancer, Macrofollicular Variant: The Follow-Up and Analysis of Prognosis of 5 Patients
}

\author{
Varlık Erol, ${ }^{1}$ Özer Makay, ${ }^{1}$ Yeşim Ertan, ${ }^{2}$ Gökhan İçöz, ${ }^{1}$ \\ Mahir Akyldız, ${ }^{1}$ and Mustafa Yılmaz ${ }^{1}$ \\ ${ }^{1}$ Division of Endocrine Surgery, Department of General Surgery, School of Medicine, Ege University, Bornova, 35100 Izmir, Turkey \\ ${ }^{2}$ Department of Pathology, School of Medicine, Ege University, Bornova, 35100 Izmir, Turkey
}

Correspondence should be addressed to Özer Makay; ozer.makay@ege.edu.tr

Received 10 June 2014; Revised 24 August 2014; Accepted 31 August 2014; Published 10 September 2014

Academic Editor: Giovanni Tallini

Copyright (C) 2014 Varlık Erol et al. This is an open access article distributed under the Creative Commons Attribution License, which permits unrestricted use, distribution, and reproduction in any medium, provided the original work is properly cited.

\begin{abstract}
Objective. The main aim of this study was to comparatively analyze the recurrence and prognosis of this rare variant with the literature by analyzing the follow-up data of 5 patients diagnosed with papillary cancer macrofollicular variant. Methods. The demographic data, radiological and pathological data, and prognostic data of 5 patients who underwent surgery for thyroid cancer and were diagnosed with papillary cancer macrofollicular variant pathologically were retrospectively analyzed. Results. The mean age of patients whose mean follow-up period was determined as 7.2 years was 41 , and the male/female ratio was $4 / 1$. All patients underwent total thyroidectomy. The pathology report of 2 patients $(40 \%)$ revealed macrofollicular variant of papillary microcancer, and 3 patients papillary cancer macrofollicular variant. Central dissection was performed in one patient (20\%) due to macroscopic pathologic lymph node and 4 metastatic lymph nodes were reported. Also, locoregional recurrence was present in 3 out of 5 patients (60\%). Conclusions. Although an impression of earlier and increased risk of recurrence in papillary carcinoma with macrofollicular variant has been documented, more studies with extensive follow-up times and large populations are required.
\end{abstract}

\section{Introduction}

Thyroid cancer is the most common endocrine malignancy, it accounts for less than $1 \%$ of all cancers, and the tumors usually progress slowly [1]. Papillary thyroid cancer is the most common of all thyroid cancers. It makes up $80 \%$ of all thyroid cancers [2]. Despite high survival rates, local recurrence and metastasis occur in some patients and this may require more aggressive surgical treatment. It is more common in women; the incidence varies according to different reports. Male : female ratio varies from 1:2 to $1: 10$. They often appear in the third and fifth decades of life $[3,4]$. Papillary thyroid carcinoma exhibits a morphologically wide spectrum. Follicular variant of papillary thyroid cancer subtypes is characterized by follicles lined by cells with nuclear features of papillary carcinoma. Follicles are usually associated with small, dense colloids [5]. Macrofollicular variant of papillary carcinoma (MVPC) is a rare subtype of follicle variant, and it was first defined by Albores-Saavedra et al. in 1991 [6] and was described as encapsulated follicular variant that includes more than 50\% macrofollicular in each section. Macrofollicle was defined as a follicle that is of a diameter greater than $250 \mu \mathrm{m}$. In this study, the aim was to examine the prognostic features of MVPC by analyzing the follow-up results of 5 patients diagnosed with MVPC.

\section{Materials and Methods}

Demographic data, preoperative data, postoperative treatment methods (hormone replacement, radioactive iodine ablation therapy), locoregional recurrence rates, and prognostic factors of patients who underwent surgery due to thyroid cancer in Ege University Hospital, Department of General Surgery, Division of Endocrine Surgery, and were diagnosed with MVPC between January 2000 and January 2006 were retrospectively analyzed.

All treatment decisions were taken by an endocrine council consisting of general surgeons, endocrinologists, nuclear medicine specialists, pathologists, and radiologists, by adopting a multidisciplinary approach. In our clinic, we applied 
total thyroidectomy for patients diagnosed with thyroid cancer, in a way that no visible tissue would be left behind.

Locoregional recurrence was described as cases having pathological lymph nodes on ultrasonography and/or cytology and/or a new determination of a previously nonexisting tissue or presence of increased levels of thyroglobulin.

\section{Results}

The mean age of the patients included in the study was 41 $(38-48)$. Four of them were females $(80 \%)$ and 1 was male (20\%). The mean follow-up duration was 7.2 years (5.3-11.2). While the reason for one patient's admission was symptoms of hyperthyroidism, no symptoms were detected in other patients. On physical examination, one of the patients had palpable thyroid nodules on right upper lobe, and another had bilateral palpable nodules. No palpable lymph nodes were detected in any of the patients. All patients had euthyroid thyroid function tests. None of the patients had thyroid cancer history in their families. None of the patients were detected to have pathological lymph nodes after ultrasonographic evaluation. All patients underwent a total thyroidectomy.

In the histological examination of tumors that were observed in thyroidectomy materials, macrofollicular structures were determined in most areas and microfollicular in some others. These cells lining the follicles were of clear nuclei and showed obvious deformity of the nuclear membrane, notch structure, and sparse pseudoinclusion. It was remarkable that a portion of the cells lining macrofollicles had hyperchromatic nuclei. Also, vacuolization was spotted in colloid in the periphery of the follicle structures. With these histological findings, the tumor found in all patients was reported to be MVPC (Figures 1 and 2). More than 50\% of the crosssectional area of the tumor was composed of macrofollicles (follicles $250 \mu \mathrm{m}$ in diameter) in all patients. Pathological tumor sizes were reported as $<1 \mathrm{~cm}$ in 2 patients, $1.1-2 \mathrm{~cm}$ in another two, and $2.1-3 \mathrm{~cm}$ in the last one. Multifocal tumors were reported in one patient. There was no tumor invasion (soft tissue, capsules, and vessels) in any of the patients. Upon detecting lymph nodes in intraoperative macroscopic pathology, one patient $(20 \%)$ was applied ipsilateral central (6th level) lymph node dissection and 4 metastatic lymph nodes were reported histologically out of 11 dissected lymph nodes.

While four of the patients (80\%) were applied radioactive iodine ablation (RIA) in the postoperative period, $1(20 \%)$ was not. The patient, who was detected to have lymph node metastases, received RIA at a dose of $225 \mathrm{mCi}$, and the other three received $<150 \mathrm{mCi}$. Locoregional recurrence was detected in three patients. One patient was operated due to recurrence, and others were controlled by RIA. Mortality was observed in none of the patients (Table 1).

\section{Discussion}

Papillary thyroid carcinoma is the most common malignant tumor of the thyroid gland, and it is in the group of welldifferentiated tumors thanks to good prognosis. It is also the type of thyroid cancer which has the widest histological

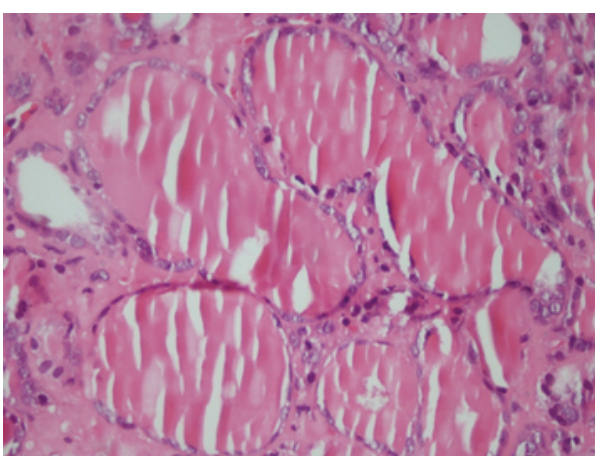

FIgURE 1: MVPC histological image (hematoxylin and eosin, $\times 20$ ).

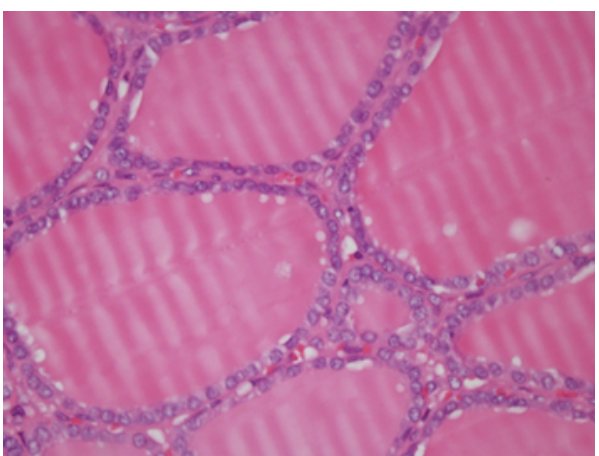

FIGURE 2: Follicular structures lined by tumor cells that include papillary carcinoma nuclear features.

spectrum. MVPC histologically consists of follicles and cells of papillary cancer nuclear characteristics which line these follicles. While macrofollicles can also be encountered in classical papillary cancer and follicular variant, more than $50 \%$ of the tumor in macrofollicular variant consists of macrofollicles. Defining this variant is important as it can easily be mistaken with benign thyroid lesions, such as nodular goiter and follicular adenoma. Macrofollicles in MVPC are lined by tumor cells with nuclei that are large, overlapping, clear, and notched and that sometimes have cores containing pseudoinclusion [7]. Minor nuclear irregularities can also be seen in benign lesions, but this histological finding is not enough for a cancer diagnosis alone [7]. In addition, unlike benign thyroid lesions, there is a remarkable nuclear deformity in the shapes of cells. Histological diagnosis is made according to nuclear properties of tumor cells paving the macrofollicles because macrofollicles are lined by squamous cells in some MVPCs [8].

Definitions as case presentations exist in the literature, the largest series of which is the one made by Albores-Saavedra et al. in 1991 with 29 patients to define MVPC and republished the results in 1997 with the adding up new cases [9]. There are no large series of patients, but it can be said that it is more common in females than males [6]. Similarly, male/female ratio was 4/1. MVPC was reported to have a very good prognosis with its lower rate of lymph node metastasis compared to classical papillary cancer $[9,10]$. Clinically, they are usually included in nonaggressive tumors, and in the study of Albores-Saavedra et al. rate of lymph node metastasis was 
TABLE 1: General characteristics of patients.

\begin{tabular}{|c|c|}
\hline & $n(\%)$ \\
\hline \multicolumn{2}{|l|}{ Age } \\
\hline$\leq 45$ & $4(80 \%)$ \\
\hline$>45$ & $1(20 \%)$ \\
\hline \multicolumn{2}{|l|}{ Gender } \\
\hline Female & $4(80 \%)$ \\
\hline Male & $1(20 \%)$ \\
\hline \multicolumn{2}{|l|}{ Ultrasonographic nodule size } \\
\hline$\leq 1 \mathrm{~cm}$ & 0 \\
\hline $1.1-2 \mathrm{~cm}$ & $3(60 \%)$ \\
\hline $2.1-3 \mathrm{~cm}$ & $2(40 \%)$ \\
\hline$>3 \mathrm{~cm}$ & 0 \\
\hline \multicolumn{2}{|l|}{ Histopathological tumor size } \\
\hline$\leq 1 \mathrm{~cm}$ & $2(40 \%)$ \\
\hline $1.1-2 \mathrm{~cm}$ & $2(40 \%)$ \\
\hline $2.1-3 \mathrm{~cm}$ & $1(20 \%)$ \\
\hline $3.1-4 \mathrm{~cm}$ & 0 \\
\hline$>4 \mathrm{~cm}$ & 0 \\
\hline \multicolumn{2}{|l|}{ Surgical technique } \\
\hline Total thyroidectomy & $5(100 \%)$ \\
\hline \multicolumn{2}{|l|}{ Histopathology } \\
\hline MVPC & $5(100 \%)$ \\
\hline Lymph node metastasis & $1(20 \%)$ \\
\hline Tumor invasion & 0 \\
\hline \multicolumn{2}{|l|}{ Postoperative treatment } \\
\hline Radioiodine ablation & $4(80 \%)$ \\
\hline$\leq 150 \mathrm{mCi}$ & $3(75 \%)$ \\
\hline$>150 \mathrm{mCi}$ & $1(25 \%)$ \\
\hline Locoregional recurrence & $3(60 \%)$ \\
\hline Radioiodine ablation (>150 mCi) & $1(33.3 \%)$ \\
\hline Radioiodine ablation $(\leq 150 \mathrm{mCi})$ & $2(66.6 \%)$ \\
\hline Mortality & 0 \\
\hline
\end{tabular}

reported as $11.8 \%$, in their second study as $20.6 \%$, and in another study by Evans as $7.1 \%$ ( 1 metastasis in 14 patients) $[6,9,11]$. In this study, lymph node metastasis rate was determined as 20\%. MVPC lymph node metastases rate's being lower while it is higher in general papillary cancer is associated with the fact that it is a well-limited capsulated and having low proliferative activity $[6,9]$.

Contrary to the abovementioned good prognostic data, 2 out of 29 patients were reported to have capsular invasion, vascular invasion, and lung metastasis in the study of Albores-Saavedra et al. [9]. Also, in the study by Cardenas et al. 2 cases with aggressive behaviour (extrathyroid extension, lymph nodes, and bone and lung metastases) were reported [12]. In this study, distant metastasis and death were not detected in a mean follow-up period of 7.2 years, and locoregional recurrence rate was observed to be high (60\%). In a study we conducted in our clinic but not yet published, 5 out of 181 patients $(2.7 \%)$ diagnosed with well-differentiated thyroid cancer were detected to have MVPC. In a mean follow-up period of 7.1 years, locoregional recurrence rate of 181 patients was determined to be $22.6 \%$ (41 patients), and the locoregional recurrence rate of MVPC group in this group of patients was found to be higher (60\%). In this small series, we describe two cases of microcarcinoma exhibiting macrofollicular architecture: these are two aspects generally correlated with an excellent prognosis. Regarding the clinical behavior of these cases in this series, one of the recurrent patients had a microcarcinoma. This patient, as well as the rest in this series, had no invasion reported on histopathological review. The other microcarcinoma patient had no recurrence during follow-up.

Although MVPC is said to be a variant that has a perfect prognosis and less rate of lymph node metastasis than those of classical papillary cancer, in this study the rate of lymph node metastasis was found to be $20 \%$ and locoregional recurrence rate $60 \%$. It can be argued that the number of patients included is not enough to make definite statements about prognosis, but studies including such large groups do not exist in the literature. Special care should be given especially because one can encounter other benign thyroid diseases in fine-needle aspiration biopsy and histological evaluation.

As its histological subtypes and the clinical behaviour of these subtypes are highly variable, this definition has started to prove insufficient though papillary cancer is one of the diseases with best prognosis. For this reason, we are of the opinion that prospective prognostic studies that evaluate all papillary cancer subtypes together with higher number of patients are a need today.

\section{Consent}

All the authors confirm that the patients have given their informed consent for the case report to be published.

\section{Conflict of Interests}

The authors declare that there is no conflict of interests regarding the publication of this paper.

\section{References}

[1] G. H. Sakorafas, J. Giotakis, and V. Stafyla, "Papillary thyroid microcarcinoma: a surgical perspective," Cancer Treatment Reviews, vol. 31, no. 6, pp. 423-438, 2005.

[2] G. P. Sadler and O. H. Clark, "Thyroid and parathyroid", in Schwartz's Principles of Surgery, vol. 36, pp. 1661-1687, McGrawHill, New York, NY, USA, 7th edition, 1999.

[3] C. A. Muro-Cacho and N. N. K. Ku, "Tumors of the thyroid gland: histologic and cytologic features-part 1," Cancer Control, vol. 7, no. 3, pp. 276-287, 2000.

[4] S. A. Hundahl, I. D. Fleming, A. M. Fremgen, and H. R. Menck, "A national cancer data base report on 53,856 cases of thyroid carcinoma treated in the US, 1985-1995," Cancer, vol. 82, pp. 2638-2648, 1998.

[5] D. Chung, R. A. Ghossein, and O. Lin, "Macrofollicular variant of papillary carcinoma: a potential thyroid FNA pitfall," Diagnostic Cytopathology, vol. 35, no. 9, pp. 560-564, 2007. 
[6] J. Albores-Saavedra, E. Gould, C. Vardaman, and F. Vuitch, "The macrofollicular variant of papillary thyroid carcinoma: a study of 17 cases," Human Pathology, vol. 22, no. 12, pp. 1195-1205, 1991.

[7] V. A. LiVolsi, "Papillary neoplasms of the thyroid: pathologic and prognostic features," The American Journal of Clinical Pathology, vol. 97, no. 3, pp. 426-434, 1992.

[8] R. A. De Lellis, R. V. Lloyd, P. U. Heitz, and C. Eng, World Health Organization Classification of Tumors. Pathology and Genetics of Tumors of Endocrine Organs, IARC Pres, Lyon, France, 2004.

[9] J. Albores-Saavedra, I. Housini, F. Vuitch, and W. H. Snyder, "Macrofollicular variant of papillary thyroid carcinoma with minor insular component," Cancer, vol. 80, pp. 1110-1116, 1997.

[10] M. L. Carcangiu, G. Zampi, A. Pupi, A. Castagnoli, and J. Rosai, "Papillary carcinoma of the thyroid. A clinicopathologic study of 241 cases treated at the University of Florence, Italy," Cancer, vol. 55, no. 4, pp. 805-828, 1985.

[11] H. L. Evans, "Encapsulated papillary neoplasms of the thyroid: a study of 14 cases followed for a minimum of 10 years," The American Journal of Surgical Pathology, vol. 11, no. 8, pp. 592597, 1987.

[12] M. G. Cardenas, S. Kini, and M. Wisgerhof, "Two patients with highly aggressive macrofollicular variant of papillary thyroid carcinoma," Thyroid, vol. 19, no. 4, pp. 413-416, 2009. 


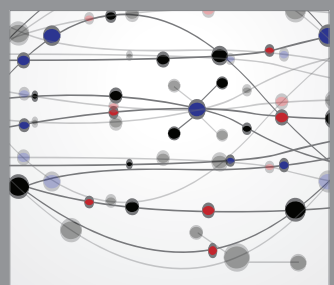

The Scientific World Journal
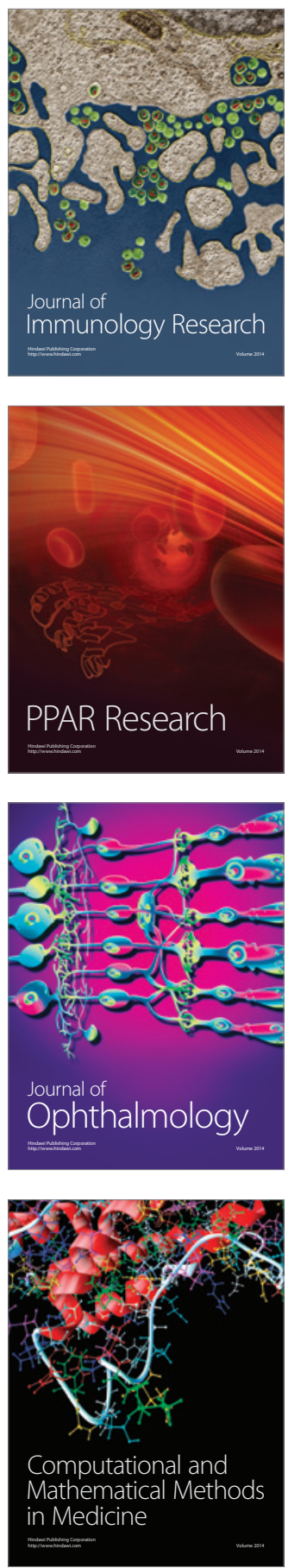

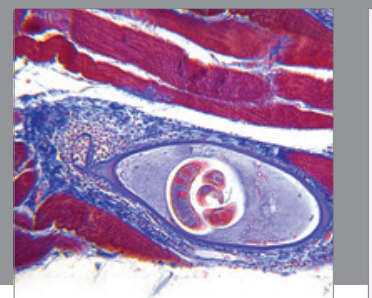

Gastroenterology

Research and Practice
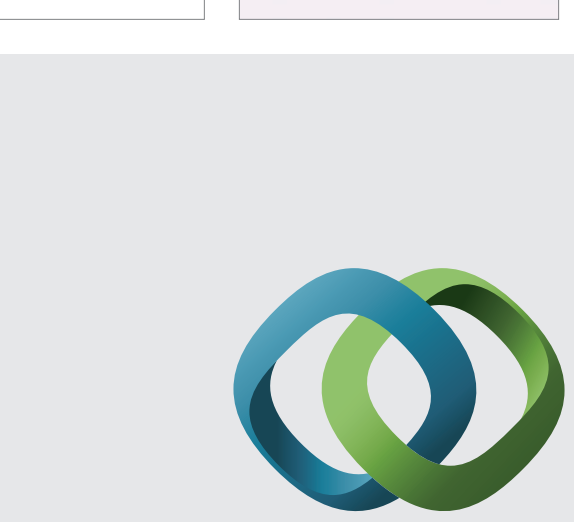

\section{Hindawi}

Submit your manuscripts at

http://www.hindawi.com
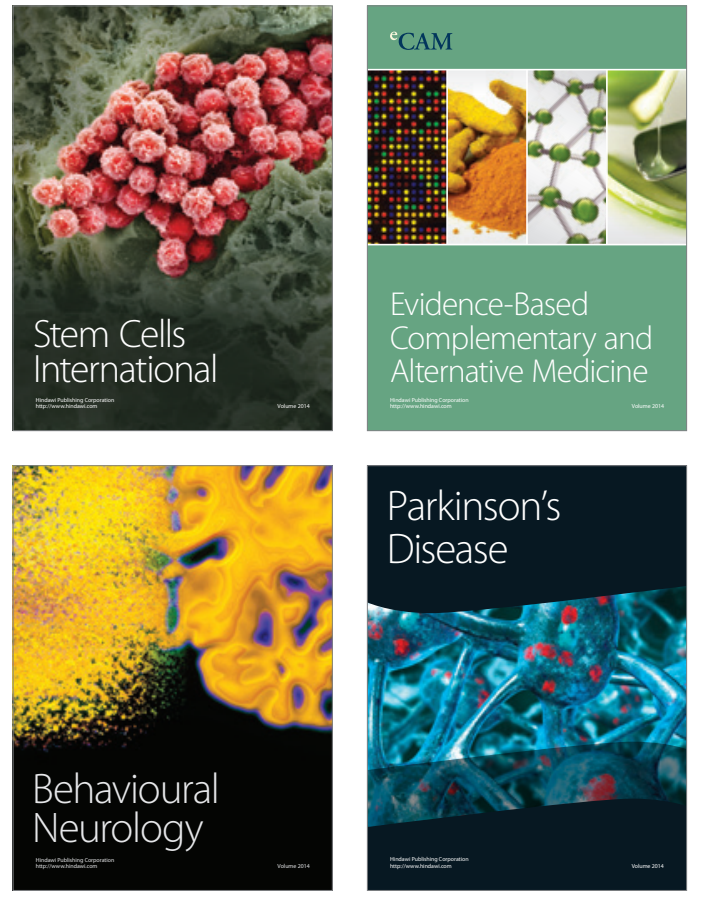
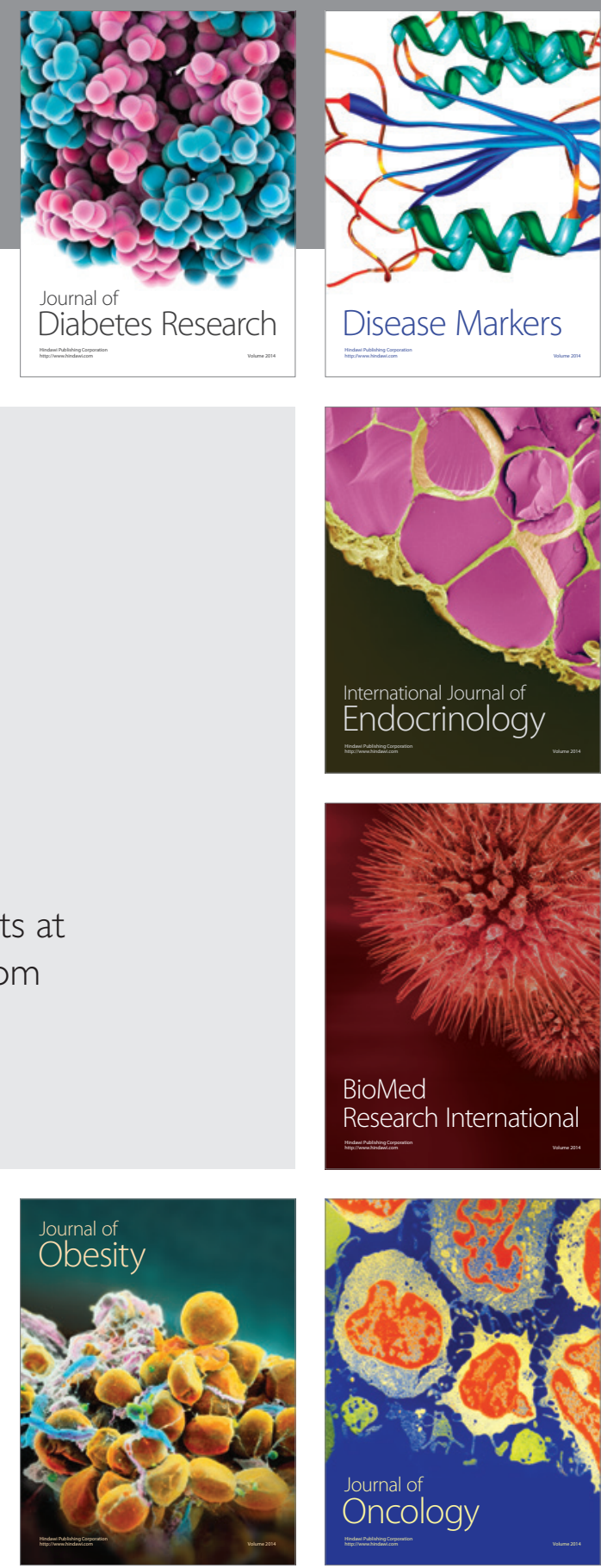

Disease Markers
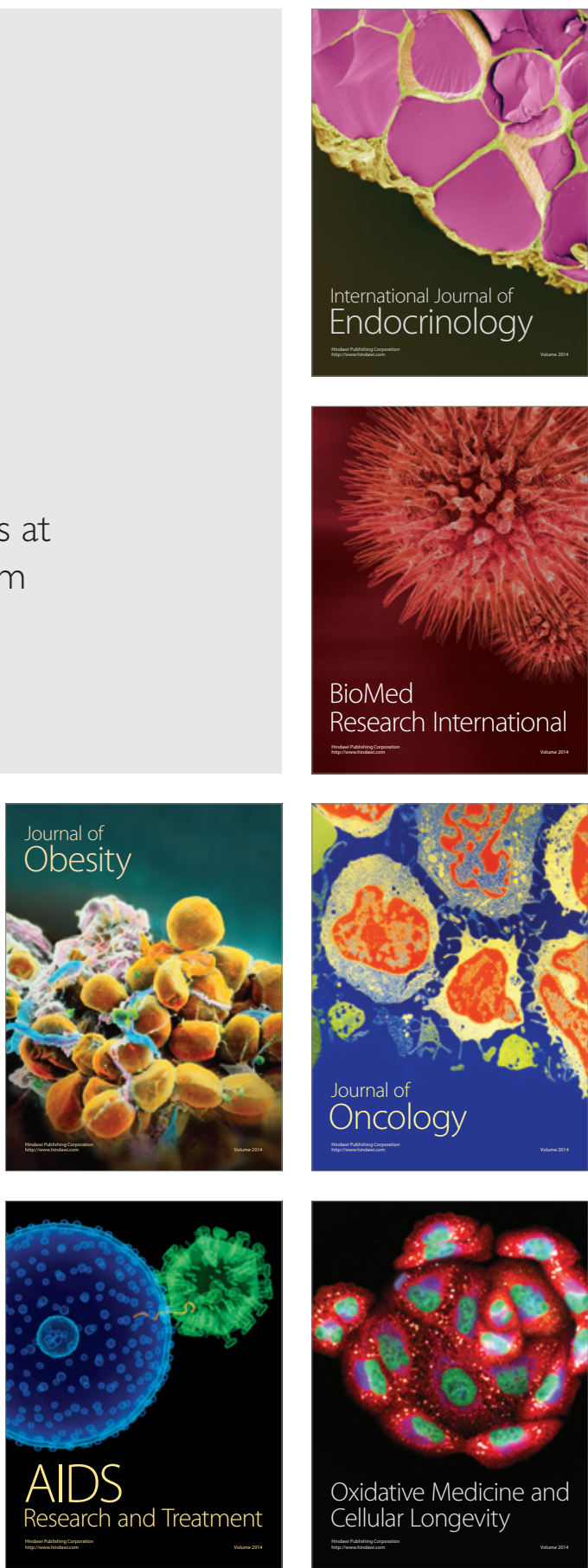